\title{
An unusual case of oesophageal rupture treated by transhiatal oesophagectomy
}

\author{
K. Park, T.J. Crofts, S.C.S. Chung and A.K.C. Li \\ Department of Surgery, The Chinese University of Hong Kong, Prince of Wales Hospital, Shatin, N.T., \\ Hong Kong.
}

\begin{abstract}
Summary: Spontaneous rupture of the oesophagus is an uncommon surgical emergency. A case is presented in which the extensive nature of the rupture precluded standard methods of treatment and was treated by transhiatal oesophagectomy.
\end{abstract}

\section{Introduction}

A recently reported series ${ }^{1}$ attributed the excellent results obtained in the treatment of spontaneous oesophageal rupture to primary suture, where possible, adequate debridement with drainage of the mediastinum and post-operative nutritional support. Other authors have also recommended early primary repair of oesophageal tears. ${ }^{2,3} \mathrm{We}$ would like to report our recent experience with a case of spontaneous rupture of the oesophagus in which this approach was not possible.

\section{Case report}

A 72 year old man was admitted with a history of severe chest pain after a bout of violent vomiting. No subcutaneous emphysema was detectable and an initial chest X-ray was normal. However, a repeat film taken 15 hours after the onset of symptoms revealed a small left sided pleural effusion. A diagnosis of perforation of the oesophagus was made. For logistic reasons contrast examination was not obtainable. The patient was brought to the operating theatre for repair of the tear. Flexible endoscopy immediately prior to surgery confirmed the clinical diagnosis - there

\section{References}

1. Hendry, W.S., Munro, A. \& Logie, J.R.C. Spontaneous rupture of the oesophagus: principles of management. $J R$ Coll Surg Edinb 1983, 31: 274-276.

2. Froggart, D.L. \& Gunning, A.J. Treatment of oesophageal perforation. Thorax 1966, 21: 524-528. being two large rents on opposite sides of the oesophagus that extended on the right side from 25 to $35 \mathrm{~cm}$ from the incisor teeth, and on the left from 33 to $38 \mathrm{~cm}$. The extensive nature of the tears made surgical approach from either side of the chest difficult. A transhiatal oesophagectomy was therefore performed, with blunt dissection of the oesophagus through an enlarged hiatus. Continuity of the alimentary tract was restored by a cervicalo oesophagogastrostomy. This technique allowed adequate drainage of the mediastinum through the hiatus and it was possible to fashion an anastomosis in the neck away from the contaminated field. Operating time was limited to 2 hours and 40 minutes. The patient made a good recovery.

\section{Discussion}

We would adhere to the principles of primary closure advocated by Hendry et al. ${ }^{1}$ but where this is not possible transhiatal oesophagectomy represents an alternative which observes fundamental surgical principles.

3. Abbot, O.A., Mansour, K.A., Logan, W.D. et al. Atraumatic, so called 'spontaneous' rupture of the oesophagus. J. Thorac Cardiovasc Surg 1970, 59: 67-83.

Correspondence: Professor A.K.C. Li, M.A., M.D., M.S., F.R.C.S.(Ed), F.R.C.S., F.R.A.C.S.

Accepted: 25 June 1987

(C) The Fellowship of Postgraduate Medicine, 1988 